\title{
Psicologia escolar e cotas raciais na educação superior: estudos em periódicos
}

\author{
brasileiros.
}

\section{School psychology and racial quotas in higher education: studies in brazilian periodicals.}

\author{
Matheus Asmassallan, Claisy Marinho \\ Universidade de Brasília.
}

\begin{abstract}
Resumo
O presente estudo busca contribuir para a discussão no cenário brasileiro acerca das ações afirmativas no Ensino Superior e sua relação com a Psicologia Escolar, a partir do levantamento de artigos nos últimos dez anos. Com base na análise de artigos de periódicos nacionais brasileiros relativos à área da Psicologia no Scielo e Lilacs, publicados entre 2006 e 2016, realizou-se um panorama de como as Políticas de Ações Afirmativas têm sido investigadas pela Psicologia Escolar. A partir deste levantamento, busca-se ampliar as possibilidades de discussões, produções, reivindicações e investigações em prol da população negra.

Palavras-chave: Psicologia Escolar, Educação Superior, Cotas Raciais.
\end{abstract}

\begin{abstract}
The present study seeks to contribute to the discussion in the brazilian scenario about affirmative actions in Higher Education and its relationship with School Psychology, from the survey of articles in the last ten years. Based on the analysis of articles from brazilian national journals related to Psychology in Scielo and Lilacs, published between 2006 and 2016, an overview was made of how Affirmative Action Policies have been investigated by School Psychology. From this survey, seeks to expand as possibilities for discussions, , productions, demands and investigations for the benefit of the black population.

Keywords: School Psychology, Higher Education, Racial quotas.
\end{abstract}

\section{Introdução}

As políticas educacionais de cada país estabelecem as oportunidades de acesso à educação, no nível básico ou superior. No caso da Educação Superior brasileira, o acesso não está garantido à toda população, diferente de outros países que possuem o ingresso sem restrições como estratégia de igualdade de oportunidade e de equidade. Nos países em desenvolvimento, a exemplo do Brasil, é perceptível o significativo aumento em termos de oferecimento e de procura por Educação Superior, muito em decorrência dos seguintes fatores: o aumento das exigências do mercado de trabalho, as políticas de melhorias da educação básica, a regência da redução das desigualdades de acesso à educação, bem como a elevação do nível de escolaridade da população para além das elites tradicionais (Bisinoto, Marinho-Araújo \& Almeida, 2011).

Nos últimos anos, tem ocorrido um grande crescimento no número de instituições, de cursos e de vagas ofertadas que contribuem para ampliação do acesso à Educação Superior e compõe o processo de democratização deste nível de ensino. No Brasil, o número de alunos novos que ingressaram na Educação Superior em 1996 foi de 513.842, enquanto, já no ano de 2013, esse número já saltava para um total de 2.742.950 (INEP, 1999, 2015). Em relação aos concluintes, o Brasil passou de 466.260, em 2002, para 991.010 concluintes em 2013, destes 76,9\% egressaram de IES privadas e $23,1 \%$ de IES públicas (INEP, 2007, 2015, 2017).

No atual cenário do ensino superior brasileiro, mudanças importantes ocorreram no âmbito da expansão e desenvolvimento deste nível de educação a partir de iniciativas como as Políticas de Ações Afirmativas, o Fundo de Financiamento ao Estudante no Ensino Superior (FIES), o Programa Universidade para Todos (ProUni) e o Programa de Apoio a Planos de Reestruturação e Expansão das Universidades Federais (Reuni). Estas mudanças passaram a exigir das instituições novas abordagens pedagógicas e administrativas, como reformulação dos projetos curriculares, dos processos de avaliação, da qualidade do corpo do docente, além da implementação do processo de inclusão e permanência de estudantes que passaram a ingressar no ensino superior (Marinho-Araújo, 2015).

Em decorrência das políticas de expansão, há um novo perfil de aluno que ingressa no ensino superior, com múltiplas demandas que indicam a necessidade de redefinir competências, tanto para os órgãos de educação brasileira, quanto para as universidades e os setores que implementam ações, de forma que as ações sejam conjuntas e não sobrepostas e contraditórias. Almeida et al. (2012), ao discutir a democratização do acesso ao ensino superior e a permanência, chamam 
atenção para o perfil dos estudantes, pois é a partir deste perfil que se entende o processo simbólico e prático da exclusão dos incluídos, pois que o estudante, até obter o sucesso acadêmico, lida com diversas dificuldades para permanecer. Dessa forma, autores questionam se a democratização do acesso ao ensino superior é efetiva e se visa o sucesso acadêmico de todos os sujeitos que se inserem, pois na inexistência das condições adequadas de permanência desses estudantes, gera-se um grande processo de exclusão social pela via da educação (Dias Sobrinho, 2008; Pan et al, 2013).

$\mathrm{Na}$ análise histórica do surgimento deste contexto de democratização do acesso e de um novo perfil de aluno que ingressa no ensino superior, tem-se a aprovação da Lei ${ }^{\circ} 12.711 / 2012$ (Lei de Cotas) no Brasil, que tornou obrigatória a reserva de $50 \%$ das matrículas para pretos, pardos, indígenas, alunos de escola pública e de baixa renda nas instituições federais de ensino superior e técnico por curso, progressivamente até o ano de 2016 (Brasil, 2012). A aprovação dessa lei no Brasil no âmbito das Políticas de Ações Afirmativas, foi gerada por uma realidade que apresentava apenas $12,8 \%$ dos negros entre 18 e 24 anos chegando no nível superior; apesar desse número representar quase o dobro entre os anos de 2005 e 2015, ainda não equivale à metade dos jovens brancos (26,5\% em 2015) (IGBE, 2016).

Neste cenário de discrepância entre negros e brancos no ingresso ao ensino superior, construir a discussão a respeito das questões étnico-raciais no Brasil é assunto que envolve uma série de complexidades e controvérsias. Apesar disso, não é mais um problema individual do negro, que era inferiorizado de forma constitucional e biológica como era antes, (Santo, Schuman \& Martins, 2012). Atualmente, nas produções científicas, essa questão é vista e problematizada como um problema relacional, onde o negro busca o reconhecimento de representações positivas (Bento, 2002). Esse trabalho se coaduna a tais pressupostos, compreendendo que as desigualdades que constituem reais abismos socioeconômicos nos diferentes grupos étnicos presentes no Brasil são de responsabilidade coletiva envolvendo, assim, toda a sociedade.

O contexto brasileiro apresenta reconhecida desigualdade racial, evidenciada por diversos estudos (Bento \& Carone, 2002; Bento 1992, 2002, 2012; Guimarães, 1999; Moura, 1988, 1989, 2004; Munanga, 1988; Schucman, 2012). Dissertações e teses (Meira, 2013; Melo, 2016; Moura, 2015; Castro, 2016; Lima, 2016; Lemos, 2015; Federico, 2014; Soares, 2014) têm sido desenvolvidos a partir do contexto das cotas raciais e que denunciam o racismo presente no ensino superior frente ao acesso ampliado da população negra. Buscando produções e concepções diferenciadas, para além da denúncia do racismo, o presente trabalho espera contribuir para a discussão no cenário brasileiro acerca das ações afirmativas no ensino superior e sua relação com a psicologia escolar, por meio da construção de um panorama de como as Políticas de Ações Afirmativas têm sido investigadas pela Psicologia Escolar nos últimos dez anos, recuperados nas bases de dados Scielo e Lilacs.

\section{Método}

O presente estudo, de base qualitativa e fundamentado na perspectiva histórico-cultural (Vygostky, 1999, 2008), se configura como exploratório e é norteado pela compreensão da realidade como um fenômeno multideterminado, dinâmico e complexo, em que o processo de estudo não se volta exclusivamente para os produtos acabados ou para os resultados finais, mas sim, para o desenvolvimento do próprio processo e dos diferentes fatores que o influenciam. Nesta pesquisa, utilizaram-se as bases de dados de periódicos nacionais brasileiros relativos à área da Psicologia nas plataformas Scielo e Lilacs. Escolheram-se estas bases eletrônicas por possibilitarem o acesso aos trabalhos recentes sobre a temática de cotas raciais e psicologia escolar.

Elegeu-se como busca os termos "psicologia escolar", "educação superior”, "ações afirmativas", “cotas raciais" no campo 'termos em português' para verificar se esse mesmo termo era ou não indexado. Como estratégia, optou-se pelo módulo formulário avançado, de forma a inserir os descritores no campo descritor $p s i$ português. O levantamento foi realizado a partir das buscas de artigos nas duas bases digitais, entre os dias 18 e 26 de abril de 2017 e foi definido o recorte temporal publicação de 2006 até 2016.

\section{Resultados}

Ao finalizar as buscas dos descritores nos resumos, palavras-chave e textos dos artigos nas bases de dados Scielo e Lilacs, o corpus da pesquisa resultou em 35 artigos, em que o achado final foi composto por 2 artigos, após a análises e triagem dos trabalhos, estabelecendo como critério de exclusão a ausência da relação entre a psicologia escolar e as políticas de ações afirmativas de cotas raciais nos artigos.

O primeiro artigo é denominado "Ações afirmativas na educação superior: rumos da discussão nos últimos cinco anos" (Guarnieri \& Melo-Silva, 2007), relativo a um projeto de mestrado. O trabalho apresenta um levantamento das produções brasileiras entre os anos de 2000 a 2005, acerca das ações afirmativas no Ensino Superior. Na pesquisa, foram utilizados os descritores "affirmative action" e "higher education ou university", onde foram encontrados 122 resumos, internacionais com maioria norte-americana, sendo somente 1 estudo sobre o Brasil.

As autoras analisaram resumos encontrados nas bases de dados eletrônicos SCOPUS e Jstor, orientadas pela Análise de Conteúdo (Bardin, 1977). Os resultados foram organizados em três unidades de análise: dicotomia entre artigos a favor ou contra as medidas; enriquecimento do debate sobre diversidade; e visualização dialética, mais integrada e reflexiva. A primeira unidade de análise é caracterizada por revisões históricas, teóricas ou práticas referentes à medidas de ações afirmativas já implantadas. Os estudos categorizados nesta unidade de análise caracterizam-se tanto pelo dimensionamento da Ação Afirmativa como alternativa de promoção de Justiça Social e reparação histórica de efeitos discriminatórios, quanto por questionamentos sobre a incumbência estatal para esse 
tipo de política pública. A segunda unidade de análise reúne trabalhos que enriquecem o debate sobre diversidade, a partir de intervenções diretas junto à população como, por exemplo, entrevistas com estudantes ou funcionários das Universidades sobre programas de ação afirmativa. A terceira unidade de análise explicita o movimento dialético, definido enquanto produções reflexivas sobre as ações afirmativas, sendo abordadas em uma perspectiva mais integrada e reflexiva sobre as consequências para a sociedade de sua implantação nas universidades. Nessa unidade predominam, portanto, estudos voltados para a pós-admissão de alunos pelo sistema de cotas, ou seja, investigação dos programas de suporte financeiro e cultural inseridos no contexto das instituições adotantes (Guarnieri \& Melo-Silva, 2007).

As autoras afirmam que as publicações explicitam a preocupação com levantamento de fatores positivos e/ou negativos associados às ações afirmativas: positivos como a democratização dos espaços de poder para toda a população. Por fim, destacam que a ênfase das pesquisas encontradas situa-se na defesa de princípios de justiça social e reparação histórica de efeitos discriminatórios, tendendo para questões mais direcionadas à promoção da diversidade cultural (Guarnieri \& Melo-Silva, 2007).

O segundo artigo é outra revisão de literatura publicada em 2013, em língua inglesa, já após a institucionalização das Cotas Raciais no Brasil pela Lei 12.771/2012. Tal produção é produto de doutorado sanduíche, intitulado "Ideology of white racial supremacy: colonization and de-colonization processes" (Nogueira, 2013), que discute como a ideologia da supremacia racial branca desumaniza e coloniza a mente de brancos e negros no Brasil. O trabalho também busca refletir sobre possibilidades de humanização e descolonização mental em ambos os grupos a partir de políticas de Ações Afirmativas, atuais na área de Educação no Brasil.

A autora busca fornecer uma articulação das compreensões sobre como o sentido da humanidade em brancos e negros é impactado negativamente pela ideologia da supremacia racial branca. Ela afirma que esses impactos são diferentes em cada grupo, em que os brancos são desumanizados por um complexo de superioridade e os negros são desumanizados por um complexo de inferioridade e que ambos são resultados de um processo histórico de colonização mental (Nogueira, 2013).

Por fim, a autora defende que para o enfrentamento de tais condições desumanas de desigualdade racial, esforços como a Lei de Políticas de Ações Afirmativas de Cotas Raciais - 12.771/2012 no ensino superior, e a Lei 10.639/2003, que torna obrigatório o ensino da história e cultura afro-brasileira e africana em todas as escolas, públicas e particulares, do ensino fundamental até o ensino médio, constituem oportunidades para a superação das condições de discriminação e preconceito racial presentes na sociedade brasileira, de forma individual e coletiva. A autora ainda destaca que, em ambas as políticas públicas, os sujeitos brancos têm a oportunidade de se relacionar com negros, bem como dialogar e, assim, respeitar os grupos historicamente marginalizados, que neste processo, ajudam a transformar a sociedade e são transformados. Por fim, Nogueira (2013) argumenta que para os negros, essas políticas podem representar uma oportunidade de se reconhecer, reconectar e curar-se, tendo como base a sua própria história e cultura. A difusão e ensino da história afro-brasileira fortalece os caminhos para busca de um reconhecimento positivo, assim como, o acesso ao ensino superior, pode oportunizar possibilidades para a população negra.

Estes dois únicos artigos foram os resultados que apresentaram uma relação entre a psicologia escolar e as cotas raciais, a partir das buscas dos descritores "psicologia escolar", "educação superior", "ações afirmativas" e "cotas raciais" nos periódicos Scielo e Lilacs, publicados entre 2006 e 2016. Pode-se perceber a escassa contribuição da psicologia e, especificamente, da psicologia escolar brasileira no que tange às Políticas de Ações Afirmativas de Cotas Raciais, bem como às contribuições para possibilidades de sucesso dos estudantes beneficiados por esta política.

\section{Discussões}

Tendo como base a análise dos dois artigos de revisão de literatura encontrados, percebe-se a ausência de produções com ênfase da psicologia escolar no que tange às políticas de ações afirmativas no ensino superior. A partir desses achados, faz-se um convite para maiores reflexões, inquietações e problematizações acerca do papel da psicologia escolar no enfrentamento do racismo ainda presente na sociedade brasileira. Como defende Bento (2014), o combate à discriminação racial deve estar apoiado em compromissos éticos na luta por igualdade, contrapondo o escasso olhar positivo sobre as trajetórias da população negra, em que estes sujeitos produzam suas narrativas, histórias, promovam mudanças, e assim, fomentem e propiciem uma maior concretitude de igualdade racial.

Após a reflexão acerca do histórico do negro no Brasil, do contexto de democratização do ensino superior brasileiro e da produção científica brevemente apresentada neste artigo, há possibilidades de focos para além da estagnação nas demandas frente ao racismo e o olhar no fracasso, como a construção de perspectivas que foquem no desenvolvimento de estratégias abrangentes e compromissadas politicamente, que busquem contribuir no enfrentamento dos desafios educacionais como o racismo institucional (Marinho-Araujo, 2004, 2007, 2015; Bento, 2014). Assim, compreende-se que com o foco da psicologia escolar ampliado, para além das denúncias de racismo, têm-se possibilidades viáveis e éticas de novas perspectivas que não sejam somente o acesso do negro ao ensino superior, mas também, sua permanência com qualidade, de forma a que o espaço da universidade contemple o seu perfil e suas demandas (Bento, 2014; Santos, 2015). 


\section{Conclusões}

Diante desta revisão de literatura sobre a discussão do cenário brasileiro acerca das ações afirmativas de cotas raciais no ensino superior e sua relação com a psicologia escolar, é possível concluir que os artigos encontrados contribuem para a compreensão da pequena produção (Guarnieri \& Melo-Silva, 2007; Nogueira, 2013), mas não de forma generalizada, em decorrência do seu recorte temporal e critérios de exclusão utilizados neste estudo. Entende-se ainda, que diante da inserção do estudante negro no ensino superior, há possibilidades de um contexto maior de discussões, produções, reivindicações e investigações em prol da população negra (Miranda, 2014).

É nesse contexto, portanto, que a Psicologia Escolar poderá promover e evidenciar possiblidades ampliadas e críticas, a partir dos novos "perfis" de educando no ensino superior, contribuindo assim para a busca de um reconhecimento positivo da população negra.

\section{Referências}

Almeida, L. Marinho-Araújo, C. M., Amaral, A. \& Dias, D. (2012). Democratização do acesso e do sucesso no ensino superior: uma reflexão a partir das realidades de Portugal e do Brasil. Avaliação, Campinas; Sorocaba, SP. 17 (3), p. 899-920.

Bardin, L. (1977). Análise de conteúdo (L. A. Reto \& A. Pinheiro, Trad.). Lisboa, Portugal: Edições 70.

Bento, M. A. S. Resgatando a minha bisavó discriminação no trabalho e resistência na voz de trabalhadores negros. Dissertação (mestrado) Pontifícia Universidasde Católica - PUC, São Paulo.

Bento, M. A. S. (2002) Pactos narcísicos no racismo: branquitude e poder nas organizações empresariais e no poder público. Tese de doutorado. Universidade de São Paulo, São Paulo.

Bento, M. A. S. (Org.) (2012) Educação infantil, igualdade racial e diversidasde: aspectos políticos, jurídicos, conceituais. São Paulo: Centro de Estudos das Relações de Trabalho e Desigualdades - CEERT.

Bento, M. A. S. (2014) Notas sobre a expressão da branquitude nas instituições. In M. A. S. Bento et al (Org.), Identidade, branquitude e negritude: contribuições para a psicologia social no Brasil: novos ensaios, relatos de experiência e de pesquisa. (pp. 231-244). São Paulo: Casa do Psicólogo.

Bisinoto, C. \& Marinho-Araujo, C. M. (2011). Psicologia Escolar na Educação Superior: Construindo possibilidades diferenciadas de atuação. In R. S. L. Guzzo \& C. M. Marinho-Araújo (Orgs.) Psicologia Escolar: Identificando e superando barreiras. (pp. 193-214). Campinas: Alínea.

Bisinoto, C., Marinho-Araújo, C. M. \& Almeida, L. (2011). A atuação da psicologia escolar na educação superior: algumas reflexões. Revista Portuguesa de Pedagogia. Ano 45-1: 39-55.

Brasil (2012). Lei n. 12.711, de 29 de agosto de 2012. Dispõe sobre o ingresso nas universidades federais e nas instituições federais de ensino técnico de nível médio e dá outras providências.
Castro, F. G. (2016). Política de cotas no Instituto Federal de Educação, Ciência e Tecnologia do Tocantins - Campus Gurupi: Reflexos da Lei $\mathrm{n}^{\circ}$ 12.711, de 29 de agosto de 2012. Dissertação de mestrado (não publicada). Universidasde Federal do Tocantins, Palmas.

Dias Sobrinho, J. (2008). Avaliação educativa: Produção de sentidos com valor de formação. Avaliação, Campinas, 13: 193-207.

Federico, R.M. (2014). Psicologia, raça e racismo: uma reflexão sobre a produção acadêmica brasileira (2001-2012). Dissertação de Mestrado (não publicada). Universidade Federal do Rio de Janeiro, Rio de Janeiro.

Guarnieri, F.V. \& Melo-Silva, L.L. (2007) Ações afirmativas na educação superior: rumos da discussão nos últimos cinco anos. Psicologia \& Sociedade, 19 (2): 70-78

Guimarães, A. S. S. (1999). Raça e os estudos de relações raciais no Brasil. Novos estudos CEBRap, $n$. 54. pp. 147-156.

INEP. (2007). Evolução da educação superior: Anos 1991-2007. Brasília: INEP.

INEP. (2015). Resumo técnico - Censo da educação superior 2013. Brasília: INEP.

INEP. (2017). Resumo técnico - Censo da educação superior 2014. Brasília: INEP.

Lemos, I. B. (2015). Cotas raciais na UFPA: as percepções de estudantes cotistas sobre suas trajetórias acadêmicas. Dissertação de mestraod (não publicada). Universidade Federal do Pará, Belém.

Lima, A. P. M. (2016). Críticas as cotas raciais: uma análise da perspectiva "populista" presente no argumento dos intelectuais contrários a política. Tese de doutorado (não publicada). Universidade de Juiz de Fora, Juiz de Fora.

Marinho-Araújo, C. M. (2004). O desenvolvimento de competências no ENADE: A mediação da avaliação nos processos de desenvolvimento psicológico e profissional. Avaliação - Revista da Rede de Avaliação Institucional da Educação Superior RAIES. Unicamp, Campinas, 9 (4): 77-97.

Marinho-Araújo, C. M. (2007). A psicologia escolar nas diretrizes curriculares: Espaços criados, desafios instalados. In: H. R. Campos (Org.), Formação em psicologia escolar: Realidades e perspectivas. (pp. 1748). Campinas: Alínea.

Marinho-Araújo, C. M. (2015). Psicologia Escolar na Educação Superior: novos cenários de intervenção e pesquisa. In C. M. Marinho-Araújo (Org.), Psicologia Escolar: novos cenários e contextos de pesquisa, formação e prática (2 $2^{\mathrm{a}}$ ed.) (pp. 133-173). Campinas: Alínea.

Meira, A. P. B. (2013). Ações afirmativas na Universidade de Brasília: a opinião das estudantes oriundas do sistema de cotas. Dissertação de mestrado (não publicada). Universidade de Brasília, Brasília.

Melo, J. F. (2016). Significado do sistema de cotas para o ingresso no ensino superior para estudantes negros de escola pública de Fortaleza. Dissertação de mestrado (não publicada). Universidade Federal do Ceará, Fortaleza. 
Miranda, S. F. (2014). Discutindo o racismo acadêmico sob a égide da psicologia social. In M. A. S. Bento et al (Org.), Identidade, branquitude e negritude: contribuições para a psicologia social no Brasil: novos ensaios, relatos de experiência e de pesquisa. (pp. 231-244). São Paulo: Casa do Psicólogo.

Moura, C. (1998). Rebeliões da senzala. São Paulo: Zumbi, 1959.

Moura, C. (1988). Sociologia do negro brasileiro. São Paulo: Ática.

Moura, C. (1989). História do negro brasileiro. São Paulo: Ática.

Moura, C. (2004). Dicionário da escravidão negra no Brasil. São Paulo: Edusp.

Moura, M. R. S. (2015). "Não é assim de graça!": Lei de Cotas e o desafio da diferença. Dissertação de Mestrado (não publicada). Universidade Federal de Rondônia, Porto Velho.

Munanga, K. (1988). Negritude: usos e sentidos. São Paulo: Ática.

Nogueira, S. G. (2013). Ideology of white racial supremacy: colonization and de-colonization processes. Psicologia \& Sociedade, 25(n. spe.), 23-32.

Oliveira, C. B. E. \& Marinho-Araujo, C. M. (2009). Psicologia Escolar na educação superior: Realidades e perspectivas no Distrito Federal. Psicologia Ciência e Profissão. Submetido.

Pan, M., Bevilacqua, C., Branco, P., Moreira, J., Litenski, A., Rhodes, C., Tovar, A. \& Zonta, G. (2013). Psicologia educacional na universidade: A construção de um modelo junto à Assistência Estudantil. Comunicação Oral apresentada no Seminário IberoAmerciano, Universidade do Vale do Itajaí, Itajaí/SC. Disponível em: $<$ http://www.acaodireta.com.br/seminarioiberoameric anoanais/piblic/docs/comunicacao-oral-20.pdf $>$ Acesso em: 12 de janeiro 2017.

Santos, S. A. (2015). O Sistema de Cotas para Negros da UnB: um balanço da primeira geração. Jundiaí, Paco Editorial.

Soares, L. M. S. (2014). População negra e ensino superior: debates sobre o sistema de cotas raciais nas universidades. Dissertação de Mestrado (não publicada). Centro Federal de Educação Tecnológica Celso Suckow da Fonseca, Rio de Janeiro.

Schucman, L. V. (2012). Entre o "encardido", o "branco" e o "branquíssimo": Raça, hierarquia e poder na construção da branquitue pauistana. Tese (Doutorado em Psicologia). Instituto de Psicologia, Universidade de São Paulo, São Paulo.

Vygotsky, L. S. (1999). Teoria e método em Psicologia. São Paulo: Editora Martins Fontes.

Vygotsky, L. S. (2008). Pensamento e Linguagem. São Paulo: Editora Martins Fontes.

\section{Agradecimentos}

Agradecimento especial ao apoio da Fundação de Apoio à Pesquisa do Distrito Federal-FAPDF na possibilidade da realização concreta deste trabalho em âmbito internacional. 